\title{
Using a Generalizable Photo-Coding Methodology for Assessing Organizational Culture Artifacts
}

\author{
Zinta S. Byrne ${ }^{1} \cdot$ Kelly A. Cave ${ }^{1} \cdot$ Steven D. Raymer ${ }^{1}$
}

Accepted: 14 September 2021 / Published online: 16 October 2021

(c) The Author(s), under exclusive licence to Springer Science+Business Media, LLC, part of Springer Nature 2021

\begin{abstract}
Despite scholars' reliance on Schein's (1990) three-interconnected layer framework of organizational culture (i.e., artifacts, values/norms, underlying assumptions), few, if any, measure artifacts. This gap is significant because artifacts are readily visible and provide valuable insight into understanding the perpetuation of norms through their manifestation in the work environment. Moreover, existing assessments focus on one layer only, either values/beliefs or underlying assumptions, resulting in only a partial picture of culture. In this tutorial-based paper, we demonstrate a grounded theory approach comprising content analysis, thematic analysis, and intensity scoring, to develop an unobtrusive method for coding artifacts seen in photos of office spaces. Unobtrusive methods reduce participant burden, which is critical because existing assessments of culture are time consuming and/or rely on numerous participants. We demonstrate how to use the photo coding method and wrap-up the tutorial by showing how artifact coding augments an existing qualitative culture assessment, emphasizing the added value of artifact assessment. We hope by providing an unobtrusive method to artifact coding, researchers will start assessing this important layer of culture to achieve a more comprehensive understanding of organizational culture.
\end{abstract}

Organizational culture is most often understood as a multiintegrated layered construct (Schein, 1990; Trice \& Beyer, 1993), ranging from observable manifestations of norms (i.e., artifacts, symbols), to espoused beliefs (i.e., values), to assumptions or unconscious beliefs (Schein, 1990). Although the layers represent different depths of consciousness to which culture manifests itself, they connect and inform the development and perpetuation of each other. As such, fully assessing and understanding an organization's complex culture requires an iterative process integrating quantitative and qualitative methods (Schein, 1990).

Yet, despite Schein's (1990) 3-layer framework of organizational culture credited for significant advances in the study of organizational culture (Chatman \& O'Reilly, 2016), we found no culture assessments that get at all three inter-related layers: artifacts (observable environment), values (espoused beliefs, norms), and underlying assumptions

Zinta S. Byrne, Kelly A. Cave, and Steven D. Raymer have contributed equally to this work.

Kelly A. Cave

Kelly.Cave@colostate.edu

1 Department of Psychology, Colorado State University, 1876 Campus Delivery, Fort Collins, CO 80523, USA (taken-for-granted and unconscious beliefs). Most reported assessments of organizational culture use quantitative methods (i.e., self-report surveys; Jung et al., 2009), which require aggregating the responses of a vast numbers of respondents, sometimes over long periods and occasionally involving more than one assessment event (e.g., Huhtala et al., 2016). In contrast, less commonly used qualitative approaches to culture assessment rely heavily on organizational immersion (i.e., ethnography) and/or time intensive interviews or focus groups (Ostroff et al., 2013). To date, we could find only one quantitative measure of artifacts (Bonavia, 2006), with the remaining quantitative measures focused on assessing practices as indicators of values (Jung et al., 2009). Nearly all qualitative approaches aim for assessing underlying assumptions and values or norms (e.g., Smollan $\&$ Sayers, 2009). Schein suggested that although artifacts do not explain why people behave the way they do in organizations, artifacts give valuable insight into the culture because they "tell us about the values and basic assumptions" (Schneider et al., 2013, p.380), and how norms manifest themselves in the work environment, which facilitates the endurance of culture.

Furthermore, although qualitative and quantitative methods of culture assessment each have their strengths, a common weakness is their reliance on engaging employees as 
informants or respondents. Hence, recent efforts to improve the measurement of organizational culture have turned to unobtrusive methods (Reader et al., 2020), such as textual analyses of existing databases, as a means for reducing the burden of extensive data collection on organizational members. Unobtrusive methods do not involve employees, providing a nonreactive approach that minimizes interruptions and lost productivity while data are collected (Reader et al., 2020). Like other advances in culture measurement, unobtrusive methods do not replace all other existing culture assessments. Using only one assessment of culture still results in an incomplete picture, regardless of assessment method (Schein, 1990). With all the assessment types noted above, data reflecting a broad range of shared group norms and attitudes are combined and analyzed to form the organizational level perspective of culture (Chatman \& O'Reilly, 2016).

Given Chatman and O'Reilly's (2016) call to reinvigorate the study of organizational culture, we sought to advance the literature by developing and demonstrating photo coding as a method of measuring artifacts. Moreover, we developed and demonstrate this unobtrusive method to encourage researchers to assess more than one layer of culture, aiming for a more comprehensive picture of culture than the single layer measured by employing a survey or set of interviews.

The primary goals of this tutorial-based paper are to describe the photo coding method for assessing artifacts, and then demonstrate how to apply this method. We then show how artifact coding augments an existing qualitative assessment of the same organizational culture, demonstrating the unique contribution artifact coding makes and why this layer in Schein's framework deserves more attention.

\section{Background}

To address the lack of a clear understanding of culture and the disparate ways academics were measuring the construct, Schein (1990) developed his three layer framework of organizational culture. Since then, this framework is frequently used as a foundational model to define the construct and to support studies that establish the pervasiveness and embeddedness of culture within organizations by assessing at least one of the layers. For example, studies employing qualitative methods, such as ethnography and interviews, extract implicit and underlying assumptions and determine how those manifest themselves in policies that create or sustain organizational norms, such as ethical or unethical decision-making (Campbell \& Goritz, 2014; Smollan \& Sayers, 2009). In contrast, quantitative methods for assessing culture are often aimed at changing the culture, such as efforts to improve organizational performance (Chatman \& O'Reilly, 2016). Existing quantitative measures like the
Competing Values Framework (CVF; Cameron et al., 2006) and the Organizational Culture Profile (OCP; O'Reilly et al., 1991 ), focus on assessing norms or values (Ghosh \& Srivastava, 2014; Rousseau, 1990), such as values for performance (van den Berg \& Wilderom, 2004) or values associated with predefined cultures like clan or adhocracy (Cameron et al., 2006).

Artifacts, though "the easiest level to observe when you go into an organization" (Schein, 1999, p.15), are typically ignored when assessing organizational culture. Observable artifacts are visible products of organizational culture created by organizational members. Artifacts may include, for example, the architecture of the physical environment, technology and products, artistic creations, style, and clothing, to name a few (Schein, 1990). We speculate the lack of artifact measurement is mainly because of a limited use of visual methodologies, such as photographs, in the organizational sciences (Ray \& Smith, 2012), and secondarily due to the ambiguity for outsiders to the organization in deciphering what artifacts mean to organizational members (Schein, 1990).

We propose using photographs of office workspaces, which capture context through imagery, to code artifacts as a cultural assessment that augments other assessments designed to measure values/norms and underlying assumptions; the other two layers of Schein's (1990) organizational culture framework. The method requires some coder familiarity with the organizational culture to overcome the challenge outsiders to the organization have in making sense of the artifacts. We first review the use of photos as data and then describe the photo coding methodology.

\section{Photos as Data}

The use of photos in qualitative research is not new. Researchers use photos to document environments, interpret phenomena, extend theory, or supplement other qualitative methodologies, such as interviews (Dacin et al., 2010; Ray \& Smith, 2012), within several different disciplines, such as management, engineering, and agriculture. These photos mainly serve to provide a visual of what the field setting looks like or to document the field setting (e.g., archeological dig site). Originating in sociological research, photo elicitation, which refers to the presentation of a photo during an interview (Collier, 1967), is a technique that uses photos to enrich the interview process. Photo elicitation may be one of the most popular uses of photos in research and has been used for many years across a variety of fields including physical education (e.g., Snyder \& Kane, 1990), tourism (Jenkins, 1999), ethnic racial studies (Winddance, 2006), and health sciences (J. Saunders et al., 2020). The specific process involves the researcher providing the participant 
with photos during the interview, and then asking the participant to provide an interpretation of what they see in the photo. Hence, the photo itself is not the actual data - rather what the participant says about the photo and their reaction to the photo serves as the data for the research study. What is in the actual photo depends on the goal of the study. For example, Wilhoit Larson (2020) had participants take pictures of their own workspace and then, while sitting with the participants looking at the pictures, asked them to describe the decorations in the workspace and how they use the space shown in their photo. A similar approach called photovoice is a method by which participants take pictures and then discuss in groups what they meant to communicate through those photos (e.g., Sarrica \& Brondi, 2020). In both approaches, photo elicitation and photovoice, the data are what the participant says and not the photos themselves. A recent advancement in photo elicitation methodology is called grounded visual pattern analysis (GVPA; Shortt \& Warren, 2019). GVPA involves participants taking their own photos of their environment, but unlike Wilhoit Larson's process, participants provide either a written or verbal narrative around the content in those photos, without the presence of the researcher. In GVPA, researchers can conduct the analysis of the photos and accompanying narrative years after the photos and narrative are collected.

Although photo elicitation and its variations reviewed briefly above support interview methods, its use can result in long, fatiguing, and emotionally taxing experiences for participants (e.g., Inés Meo, 2010), thereby defeating our aim for an unobtrusive method of culture artifact assessment. However, Wong et al., (2011) took an approach to the use of photos as data that provided insight for our development of an unobtrusive culture assessment. Using a ruler and likesized published photos of various companies' chief executive officers (CEO), the authors measured the width to length ratio of the CEOs' faces and related the ratio to archival data of company performance. The authors proposed, based on evolutionary suppositions, that physical characteristics, in particular those indicating physical strength and an ability to dominate others (Haselhuhn et al., 2015), influence leaders' effectiveness. The authors consistently found that CEOs whose faces were wider than long, indicating a more physically imposing leader, ran companies that achieved higher financial performance than those run by CEOs with a greater length to width ratio face structure. Wong et al. (2011) basically coded the image in the photo, which led ua to the idea of coding the contents of a workspace from a photo of that setting.

A benefit of using photos as data, though not incorporated in Wong et al.'s (2011) study, is that photos allow for the investigation of phenomena in their natural setting. Specifically related to organizational culture assessment, within the photos one can directly observe artifacts of culture in context (i.e., naturalistic orientation; Brewer, 2004). Thus, researchers can investigate reflections or manifestations of culture (i.e., artifacts) in an unrestrictive manner and in their natural setting. Lastly, photos enable the researcher to capture data from a wide range of organizational perspectives. For example, researchers can take photos of offices, meeting rooms, lunch or mailroom areas, and other spaces of the organization.

Furthermore, organizational researchers often neglect the voices of organizational members in their data collection, instead focusing on leaders or executive-level members as informants of organization-wide views. This narrowing of perspective created by relying only on executives as participants is particularly limiting in organizational culture assessment, as researchers have identified that subcultures exist and organizations may not have or be a single culture (Martin, 2002; Schneider et al., 2013). Photo coding widens the perspective by not relying on organizational members for data. Considering that artifacts are themselves visible products of how culture is manifested, and that photos portray contextual elements, we propose the value of photos is elevated when used as a method for assessing this layer of organizational culture.

Our focus in this tutorial-based paper is on demonstrating how to use our photo coding method. Our method is a generalizable unobtrusive approach of artifact assessment that could augment other assessments of culture aimed at measuring norms and underlying assumptions. The way in which employees interact with their supervisor, or whether there are clients, customers, students, or constituents does not matter, since every organization has artifacts. Thus, regardless of the setting or how people interact, whatever space individuals' consider their work-space will include artifacts that represent norms of the organization; therefore, researchers can apply our method in just about any organization.

In this next section, we provide an overview of our new method for using photos of work settings for assessing artifacts, the most visible of the three layers of culture identified by Schein (1990). We then provide a detailed example of how this method can be applied using photos of employee offices.

\section{Overview of the Photo Coding Methodology}

Photo coding of potential artifacts involves two phases: photographing the work setting and qualitative content analysis.

\section{Phase 1: Photos of the Work Setting}

Photography of the work setting is useful for culture assessment through its visual representation of organizational elements at the time of assessment. To be useful, the 
photographs need to capture as many potential artifacts as possible. This means taking multiple photographs of each space, if necessary, to capture the full context of the work setting. For example, photos might include offices, meeting rooms, hallways (especially to capture if the hallway is decorated or not decorated), lunch rooms (if they exist), mail rooms (if they exist), furniture, walls, desks, uniforms (if present), non-work items (if present), etc. It is not known a priori which artifacts are more meaningful than others; however, because we suggest pairing photo coding with other methods of culture assessment, information about the culture gleaned from other assessments could inform the artifact sampling approach.

Researchers should take photographs of different work spaces/settings throughout the organization at roughly the same time for two important reasons. First, doing so contributes to the stability and reliability of the information. Second, avoiding large gaps of time between photos ensures the contextual environment and artifacts are not dramatically changed due to the implementation of new branding strategies or other substantial changes to artifacts that may represent or be interpreted as efforts to change culture. Unless the objective is to assess the change in artifacts resulting from efforts to change the organizational culture, one should aim for capturing the artifacts at a single point in time. Although culture change involves much more than simply changing the office environment, some efforts to change and solidify culture include altering the work environment with the intent to embed employees within a new visual manifestation of the desired future culture (as an example, see Andrus, 2019 story of Traeger).

\section{Phase 2: Qualitative Content Analysis}

After taking photos, the next step is to perform a content analysis and a thematic analysis of the photos, which is similar to previous photo research (Ray \& Smith, 2012). The overall process requires at least two coders. First, having two coders ensures diversity of perspectives on analyzing and interpreting the data (Saldaña, 2009). Second, having coders first code independently and then check their agreement at each stage of coding ensures the coders are consistent with the assignment of codes and contributes to reliability (Saldaña, 2009). Conducted in this way, their collaborative coding increases rigor of the process and strengthens the quality of emerging results (Charmaz, 2006).

Coders should use a multi-round consensus approach toward coding, such that between each completed photo coding, raters discuss their independent ratings to form a consensus of labeling and what they consider as artifacts in the work environment. Thus, coders follow a grounded theory approach to content analysis, capitalizing on its iterative process of generating categories from emerging properties of the data (Gioia et al., 2013). Since there is subjectivity to the coding process, the multi-round consensus approach characteristic of qualitative methods is a way of dealing with subjectivity and adding rigor (reliability) to making sense of images and deriving meaningful labels (Saldaña, 2009). By converging on similar interpretations of the data, the coders develop labels and categories with robustness and transferability (Potter \& Levine-Donnerstein, 1999). We employed established strategies for ensuring rigor throughout the entire research process (Morse et al., 2002), including researcher responsiveness (challenging, openness, creativity of ideas), methodological coherence (alignment between research question, method, and analyses), and sampling adequacy (appropriate sample, achieve saturation: i.e., indicator for stopping data collection and/or analysis; indicates sufficient purposive sampling; B. Saunders et al., 2018).

We applied Schein's (2010) model, defining artifacts as visual products or palpable representations of structures and processes, which act as symbolic reflections of the espoused beliefs or values of the organization. To reduce subjectivity and increase the generalizability of artifact recognition and application to other settings, we applied characteristics in our coding that detail the purpose of artifacts in the organizational context, a technique highlighted recently in applying the study of artifacts in modern organizations (Akemu \& Abdelnour, 2020). Thus, we identified office artifacts based on three main characteristics: (1) form, the presence of purposeful or experienced design, architecture, or spatial arrangement; (2) function, the utility of objects for performing roles or contributing to the character of an office, and (3) social agency, the use of artifacts to reflect personality or individualization in an office setting. For instance, we identified a desk and its location (form), whether it had a computer and papers on it (function), and whether the items on the desk were neatly organized, and whether there were personal items (e.g., photos, decorations) or work-related items only on the desk (social agency).

Content and thematic analysis involves assigning three different levels of codes to the artifacts $\left(1^{\text {st }}\right.$ order, $2^{\text {nd }}$ order, and $3^{\text {rd }}$ order). Levels are also referred to as stages or cycles in which data are examined and compared, coded, compared across codes, and ultimately combined and categorized to capture the emergent meaning or theme (Saldaña, 2009). In this way, artifacts that are consistent across offices emerge as data reflecting organizational norms. Separating coding into a unique stage allows coders to conduct a reality check and maintain consensus in coding at each progressive stage. The $1^{\text {st }}$ order code given to data represents basic but detailed information about the contents of the workspace. The $1^{\text {st }}$ and $2^{\text {nd }}$ order codes are determined consecutively, whereas the $3^{\text {rd }}$ order code is determined after intensity scoring. 


\section{Assigning $1^{\text {st }}$ order codes}

Content analysis starts by cataloguing and assigning detailed descriptions to an initial observation of each artifact identified in the photo. The process relies on rich details and descriptions to move from specific examples to general categories that inform representative concepts from the data (Fairhurst \& Putnam, 2019). As coders analyze each new photo, they merge overlapping codes and subdivide others to reflect distinctive patterns in artifacts. Thus, the process involves constant emergence and refinement of the codes.

\section{Assigning $2^{\text {nd }}$ order codes}

After assigning every artifact a detailed description, coders should note themes arising across different types of descriptions and discuss them to reach consensus for each type of theme. Thus, coders use thematic analysis to develop the $2^{\text {nd }}$ order code from these identified themes or patterns that emerge from the descriptions of the contents of the workspace. The overall coding process is iterative, requiring some flexibility with the generation and application of codes. The descriptions and themes of artifacts arise from observations, previous knowledge of norms and expectations, and inferences of the workplace settings. Coders should use caution in assigning descriptions and themes, treating each new workplace setting with a fresh perspective, and not artificially forcing meaning onto artifacts based on codes from a previous photo/setting. One method to maintain perspective of each setting is through the use of a special identifier for each artifact, which is an additional observation separate from the three tiers of coding from content analysis. Coders note why the artifact is important and describe its use. Coders then apply intensity scoring, described next, prior to determining and finalizing the $3^{\text {rd }}$ order codes.

\section{Assigning intensity scores}

Chatman and O'Reilly (2016) proposed that norm strength, determined through culture assessment, should reflect not only the consensus or agreement of a norm, but the intensity or force with which the norm is held. An intensity score represents the degree to which cultural elements (artifacts, norms, and assumptions) are held, emphasized, or represented in an organization. When applied to norms, intensity is characterized by members' compliance and agreement towards perceived norms. Thus, the more intense a norm, the more the organization reinforces and perpetuates the norm; cultures with a low tolerance for norm violations would have high intensity scores. We extrapolated the concept of compliance, representing intensity by the degree to which an artifact compared with similar artifacts across office settings in the organization. Importantly, coders compare the artifacts based on their relationships with other artifacts in the same organization, given how loosely or tightly the artifact held to a certain standard or average across offices within the organization.

We used a Likert-type scale to assign an intensity score to artifacts to indicate the degree to which the artifacts varied in uniqueness from the rest of the office environment. Coders assign an intensity score on a 1 to 5 rating scale to each artifact. It is important for coders to agree on how the intensity scores reflect the artifacts. For example, for coding office spaces, our intensity decisions were based on usage of space (more usage equals higher intensity), the amount of objects (more objects/clutter equals higher intensity), and types of objects (strongly themed or fancy objects equals higher intensity). Alongside making comparisons with similar artifacts from other offices, we further delineated artifact intensity based on variance in uniqueness, or distraction, from the rest of the office environment. For instance, the less similar the artifact in one office compared to others would result in a score of 1 (lowest intensity), indicating a lack of norm strength or agreement of a norm. Similar to content analysis of photos, coders should determine intensity scores using a multi-round calibration method that allows for discussion and consensus on the scoring process for each artifact.

\section{Assigning $3^{\text {rd }}$ order codes}

After coders assign every description (i.e., $1^{\text {st }}$ order code) to a theme (i.e., $2^{\text {nd }}$ order code) and applied intensity scores, coders should then use axial or theoretical coding (Charmaz, 2006; Saldaña, 2009), which develops broader categories that capture the essence of related themes. In the vernacular of the qualitative method of content analysis, the broader categories are referred to as dimensions (Gioia et al., 2013), which we refer to as $3^{\text {rd }}$ order codes. Names for $3^{\text {rd }}$ order codes emerge from patterns in the themes and how the broader category reflects the organizational members' lived experience of their work space. Coders should discuss descriptors and agree on labels that reflect the related themes comprising each $3^{\text {rd }}$ order code. Intensity scoring facilitates the process of finalizing $3^{\text {rd }}$ order codes.

Phase 2, therefore, concludes with a list of every observed artifact tied to its corresponding work setting/photo, with an initial description ( $1^{\text {st }}$ order code $)$, a theme ( $2^{\text {nd }}$ order code $)$, and generalized dimension ( $3^{\text {rd }}$ order code) that can be tied to other cultural norms and assumptions (see Fig. 1 for an example of the structure of coding). At the end of Phase 2, all data have been effectively combined to represent organizational culture. 


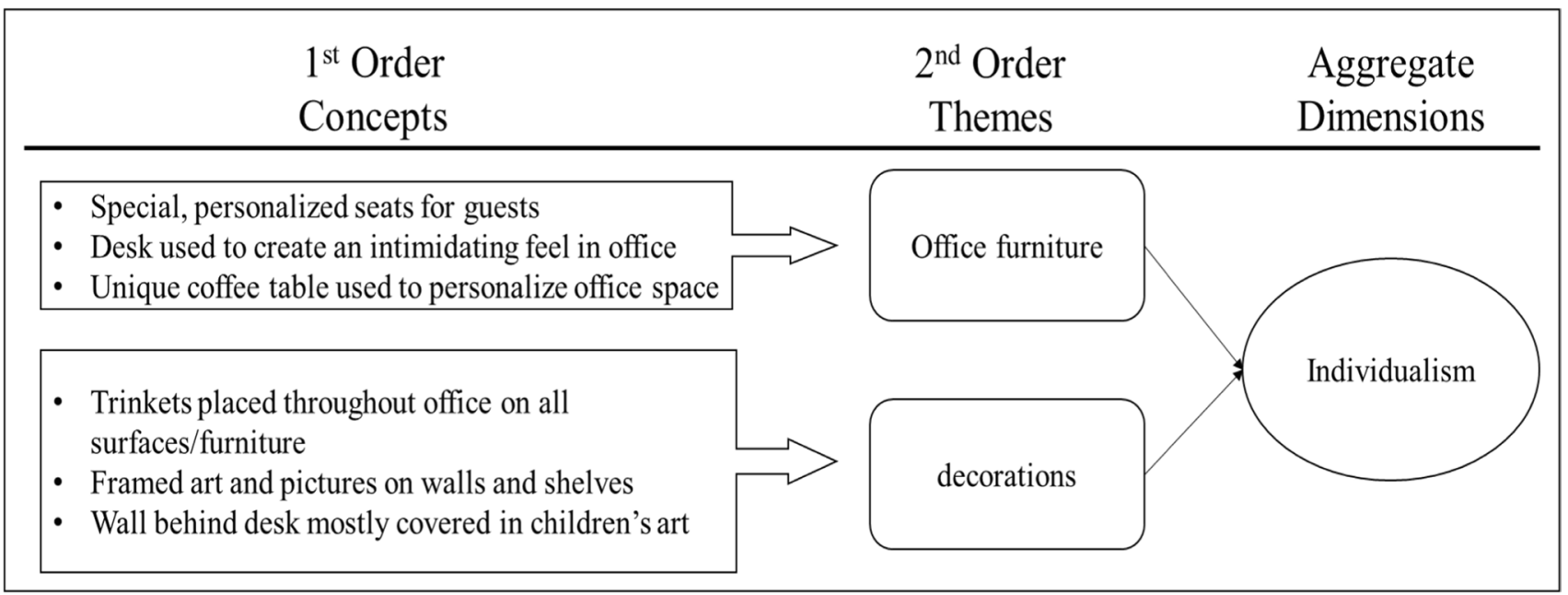

Fig. 1 Example of Coding Structure

\section{Tutorial: How to Assess Artifacts Using Photo Coding}

We now illustrate how to use our photo coding method (see flowchart of steps in Appendix) by applying it to identify cultural artifacts in university faculty offices of several departments at a mid-west, mid-sized R1 (high research productivity) university. The coding development project was part of a field study on organizational change resulting from curriculum improvements within an engineering department. Thus, the focus of our project was on departmental culture. The field study, part of a 5-year grant project supported by the National Science Foundation, was conducted by the first author of the current study, who was a Co-Principal investigator on the grant and responsible for assessing organizational culture.

\section{Phase 1: Photographs}

The first author of this paper took photos of offices in 2017 in the following university departments: electrical engineering (10), communications (8), english (9), and biochemistry and molecular biology (4), for a total of 31 office spaces. The researcher only took pictures of workspaces relevant to faculty in each department because the focus of the project was on department culture. Offices were occupied by 18 females and 13 males, ranging in age from 30 to 61, who held various positions within faculty ranks including non-tenure track instructor, assistant professor, associate professor, and full professor. Given that organizational culture has a pervasive effect on all organizational members (Chatman \& O' Reilly, 2016), which means that any randomly selected office should have cultural artifacts that represent the whole, we chose to randomly photograph offices in each participating department. From a list of office numbers provided by each department office manager, the first author used a random number generator to select which offices to photograph, only taking photos with permission from the occupant who left the room during the photo session. Therefore, there were no photos of people working in the space. In nearly all cases, the researcher took more than one photo to capture the entire space and its contents, including walls, floors, behind doors, cabinets, and around desks. The first author then blurred all identifying objects, such as name plates or faces in framed photos, within the office photos before randomly numbering the photos. Figures 2 and 3 show examples of photos of two different offices. The second and third authors of the current study, who had no exposure to the offices or their occupants, conducted the content analysis.

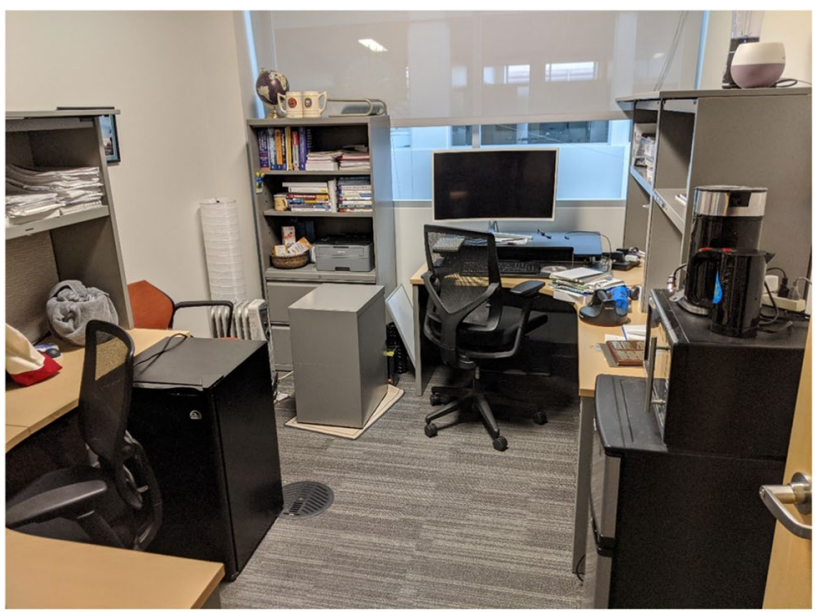

Fig. 2 Sample Office Photo 1 


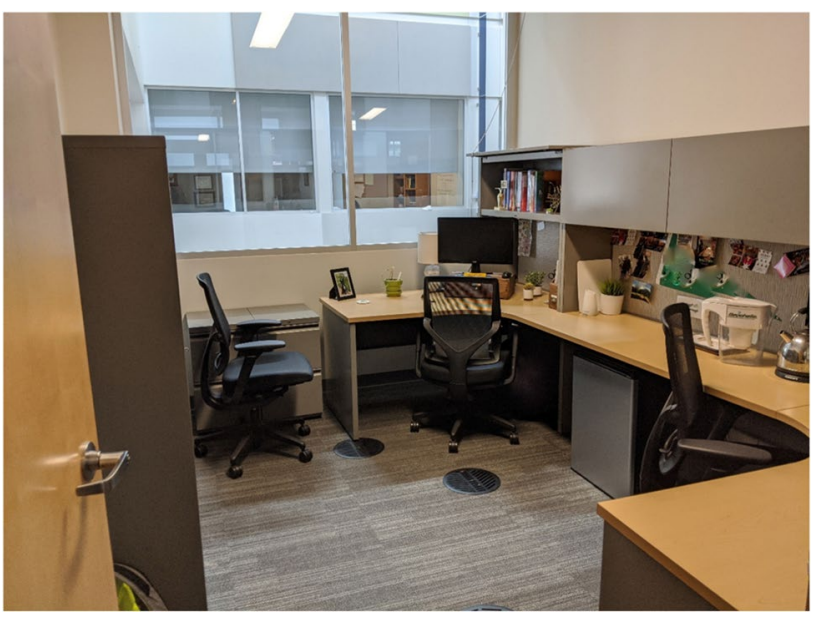

Fig. 3 Sample Office Photo 2

\section{Phase 2: Qualitative Content Analysis}

\section{First order codes}

We defined artifacts as visual products or palpable representations of structures and processes, which act as symbolic reflections of the espoused beliefs or values of the organization (Schein, 1990, 2010). We began reviewing the photos, documenting form, function, and social agency. For example, using Fig. 2, we identified a desk on the right of the photo (i.e., form), described its size and quality (e.g., L-shaped desk, seating for one, metal shelving on one side), noted how the desk was being used based on its position in the office (e.g., situated in one corner; one half is for computer, monitor, and phone; other half includes work space), presence of work-related material (e.g., papers, books, computer; function), and level of clutter (i.e., a little cluttered, organized, neat), as well as personal items (e.g., mugs, coffee maker; social agency). In Fig. 3, personal items (social agency) included plants, photo on desk, lamp, and water kettle. Other artifacts in Fig. 2 include the office chair, one picture on the wall, carpeting, metal book case, door, space heater, refrigerator, microwave, and interior facing windows. In both photos (Fig. 2 and 3), we noted the relatively uncluttered floor space allowing access in and out of the office.

The coding process did not involve organizational members; the research team (i.e., second and third author) completed all the coding. After coders made their independent ratings, they made regular comparisons of the codes (e.g., every three office spaces) to achieve and maintain consensus of the coding throughout the process. Coders reviewed each photo coding line by line, and the first author checked them to achieve final consensus.

During our initial review, we first identified concepts prevalent in each office, focusing specifically on objects, architecture, and use of space. Upon identifying an artifact, we included a description of the potential norms or assumptions associated with the artifact to help delineate thematic elements generalized for $2^{\text {nd }}$ order coding from the aggregate dimensions formed at the $3^{\text {rd }}$ level of coding. For example, using Fig. 3, we coded the chair not positioned at a desk and clearly not used for the desk occupant with collaboration, as indicating a visitor chair for meetings with the occupant(s). As coding took place, we noted how often new codes emerged and found after coding 31 office spaces no new codes emerged (i.e., saturation; Charmaz, 2006). We identified a total of 765 artifacts across the 31 office spaces. We then proceeded to the next step of content analysis, moving from $1^{\text {st }}$ order concepts to specification of $2^{\text {nd }}$ order codes.

\section{Second order codes}

The next step in our process involved a thematic analysis, which advances the observation of artifacts to patterns or manifested norms (Ray \& Smith, 2012). We identified basic thematic elements of each artifact, which led to the emergence of four generalized artifact themes: office furniture, work supplies, decorations, and office structure/design. After assigning a generalized theme to each artifact, we added a short descriptor as a special identifier to the theme based on the $1^{\text {st }}$ order coding of the artifact. While the generalized themes allowed for grouping at the $2^{\text {nd }}$ order level, we used the special identifiers to help characterize each particular artifact within an assigned theme. This characterization is useful for maintaining the original context of the artifact, while also allowing for assignment to aggregate themes (see Table 1). For example, we described a piece of children's artwork based on its prominence and positioning within the office and placed it under the theme of decorations. As another example, office equipment such as the monitor, printer, and phone shown in Fig. 2, which bore no unusual substantive qualities (e.g., standard equipment), was categorized under office supplies, given special identifiers related to the function (e.g., electronics, tools), and further aggregated under the dimension of common items.

\section{Intensity Scoring and Third Order Codes}

We assigned each identified artifact with an intensity score on a 1 (lowest) to 5 (highest) rating scale. Alongside making 
Table 1 Theme Organizing Framework

\begin{tabular}{|c|c|c|c|c|}
\hline & Artifact $\left(1^{\text {st }}\right.$ order code $)$ & Special Identifier & $\begin{array}{l}\text { Generalized Theme }\left(2^{\text {nd }}\right. \\
\text { order code) }\end{array}$ & $\begin{array}{l}\text { Aggregate Dimen- } \\
\text { sion }\left(3^{\text {rd }} \text { order }\right. \\
\text { code })\end{array}$ \\
\hline Example 1 & Wall & Personal pictures & Decorations & Individualism \\
\hline Example 2 & Desk & Cluttered & Office Furniture & Workstyle \\
\hline Example 3 & Personal Item & Plant & Decorations & Individualism \\
\hline Example 4 & Electronics & Two monitors & Office Supplies & Workstyle \\
\hline Example 5 & Floor & Cramped floor space & Office Structure/Design & Functionality \\
\hline Example 6 & Seating & One extra chair for guests & Office Furniture & Collaboration \\
\hline Example 7 & Shelving/ Storage & 3 full bookcases & Office Furniture & Workstyle \\
\hline Example 8 & Tool & Books & Office Supplies & Common items \\
\hline Example 9 & Windows & No windows & Office Structure/Design & Department Politics \\
\hline Example 10 & Setting & Shared & Office Structure/Design & Department Politics \\
\hline
\end{tabular}

comparisons with similar artifacts from other offices, we further delineated artifact intensity based on variance in uniqueness, or distraction, from the rest of the office environment. We determined where broader categories emerged based on comparing compared second order codes to one another. Intensity scores facilitated the final categorization of $2^{\text {nd }}$ order codes into nine $3^{\text {rd }}$ order codes, also known as aggregate dimensions. Table 2 shows the definitions for $3^{\text {rd }}$ order codes (i.e., dimensions).

\section{Results of Photo Coding}

Table 2 lists the nine dimensions of culture identified from the artifacts. An example of how to interpret a dimension includes that in this organization's culture, collaboration is a norm manifested in the artifacts. Artifacts such as two or more visitor chairs in an office, and/or an extra table (not the main office desk) of smaller coffee-table size situated by the visitor chairs and not covered with papers, books, phone, or computer indicated occupants might visit or otherwise meet with people in their office. Nearly all offices had visitor chairs. The average intensity score for these artifacts was 4 , which indicates meeting with people in one's office for a long enough time that chairs are required and a table for placing books, notes, laptop, or coffee mug is necessary, is an important norm.

Our coding of organizational artifacts provides an assessment of a key layer of Schein's (1990) three-layer model of how culture is manifested, and thus is intended to augment assessments of the other layers of culture, thereby providing a complete and comprehensive assessment of organizational culture. Artifacts represent manifestations of cultural values

Table 2 Definitions of Photo Coding Dimensions

\begin{tabular}{ll}
\hline Dimensions & Definition \\
\hline $\begin{array}{l}\text { Collaboration } \\
\text { Common items }\end{array}$ & $\begin{array}{l}\text { The act of working with others towards a shared goal (either within the department or outside of the department) } \\
\text { Standard office supplies and equipment that are used to perform work-related tasks (e.g., printer, stapler, books, desktop } \\
\text { monitor) } \\
\text { The floor space is designed to maximize utility or encourage user-oriented behavior } \\
\text { Functionality } \\
\text { Thdividualism } \\
\text { The extent to which an individual displays personally meaningful actions, values, or objects that may or may not be } \\
\text { werformance (success) }\end{array}$ \\
$\begin{array}{l}\text { The desire for individuals to be the best at their job, perform to their full potential, and demonstrate meaningful contri- } \\
\text { butions } \\
\text { Interactions and norms that promote displays of power and authority. Certain policies may benefit some while harming } \\
\text { others }\end{array}$ \\
$\begin{array}{l}\text { Observable distribution of resources across the department potentially indicating department values and/or priorities } \\
\text { Resource implications } \\
\text { The ways in which employees talk to one another and interact in non-work-related engagements inside or outside of } \\
\text { work }\end{array}$
\end{tabular}


and assumptions in physical space. They can stand alone as potential representations of the culture, and therefore, could tell a story about organizational culture, but the story is an incomplete one, just as only assessing culture via a survey or interviews is incomplete (Schein, 1990). Thus, in this next section we leverage an existing assessment of values completed in this same organization to illustrate how our photo coding of the artifacts augments that assessment.

\section{How to Use Artifact Coding with Other Culture Assessments}

About one year before the photo coding method was developed, the same two independent coders for the photos used grounded theory to code interview data collected by the first author, in the same organization from a subset of the same people whose offices were photographed. The coders were not aware at the time of the interview coding that the first author had taken photographs of offices or that a year later they would be asked to develop a coding method for photos.

The same coders coded across the two efforts for a few reasons. First, Schein (1990) suggested that one potential problem with researchers studying the organizational artifacts who are external to the organization is that without understanding how to connect the artifacts to underlying assumptions, they are likely to make incorrect inferences from the artifacts. By engaging in the intensive and iterative interview coding process from the prior cultural assessment, the coders (and first author) became aware of and appreciated many of the underlying assumptions, perceptions, and values of the organization. This basic understanding of the culture thus allowed the coders to identify content within the photos as artifacts rather than simply as items in a room. As Pratt (2009) states, "having someone else code your data does not necessarily make it valid" (p. 859). He further adds it makes no sense for someone who knows nothing about the context of the organization to do the coding. Gaining the rich experiences with the data over time "can and should change how you view the data" (p. 859). Because the amount of time between projects was about a year, the coders did not remember the exact details of the interview coding, including codes, themes, or dimension names. Hence, their artifact coding was informed by knowledge of the organization but not dictated by previously identified labels.

Second, the use of the same coders across studies (i.e., photo coding, interview coding) is an approach consistent with naturalistic orientation, which refers to understanding social phenomena in their natural setting (Brewer, 2004). The aim of naturalistic orientation is to understand individual's actions, experiences, and motivations, and this knowledge is obtained through familiarity with the individuals and/or the social environment being studied (Brewer, 2004). The two coders were familiar with the overall social environment of the organization - that is the university setting - but not the individuals themselves or their offices. The naturalistic orientation is frequently associated with the ethnographic approach to understanding culture (Brewer, 2004).

Lastly, to effectively resolve inconsistencies and extract connections between the layers of culture, one must become familiar with the layers, both in breadth and depth, so as to be able to see the connections and recognize the inconsistencies (Schein, 1990). "There is no way of knowing whether the dimensions one is asking about are relevant or salient in that culture until one has examined the deeper levels of the culture" (Schein, p. 112).

We compared and combined the final photo coding dimensions with themes developed during the previously conducted culture assessment. Overall, we extrapolated 16 aggregate dimensions from both the interview and artifact data (see Table 3). Seven of the dimensions were specific to the interview data, three were specific to the artifact data, and six were shared across interviews and artifacts. Table 4 provides a complete list of dimensions and their definitions.

\section{Overlapping Dimensions}

Aggregate dimensions that appeared in both interview coding and artifact coding indicate that shared meaning
Table 3 List of Aggregated Dimensions

\begin{tabular}{lll}
\hline Interview Dimensions & Artifact Dimensions & $\begin{array}{l}\text { Overlapping Dimensions (found } \\
\text { in both Interview and Artifact } \\
\text { coding) }\end{array}$ \\
\hline Inequity & Common items & Socializing \\
Support & Functionality & Performance (success) \\
Department values & Resource implications & Workstyle \\
Research & & Individualism \\
Development & & Collaboration \\
Power & & Department politics \\
Job design (role clarity) & & \\
\hline
\end{tabular}


Table 4 Definitions of Aggregated Dimensions ( $3^{\text {rd }}$ order codes)

\begin{tabular}{|c|c|c|}
\hline Dimensions & Source & Definition \\
\hline Collaboration & Both & $\begin{array}{l}\text { The act of working with others towards a shared goal (either within the department or outside of the } \\
\text { department) }\end{array}$ \\
\hline Politics & Both & $\begin{array}{l}\text { Interactions and norms that promote displays of power and authority. Certain policies may benefit some } \\
\text { while harming others }\end{array}$ \\
\hline Individualism & Both & $\begin{array}{l}\text { The extent to which an individual displays personally meaningful actions, values, or objects that may or } \\
\text { may not be work-related }\end{array}$ \\
\hline Performance (success) & Both & $\begin{array}{l}\text { The desire for individuals to be the best at their job, perform to their full potential, and demonstrate mean- } \\
\text { ingful contributions }\end{array}$ \\
\hline Socializing & Both & $\begin{array}{l}\text { The ways in which employees talk to one another and interact in non-work-related engagements inside or } \\
\text { outside of work }\end{array}$ \\
\hline Workstyle & Both & The way an individual conducts their work in terms of office use and working norms \\
\hline Job design (role clarity) & Interview & Clarity surrounding assigned responsibilities, and how aspects of the job appear to be valued and rewarded \\
\hline Power & Interview & $\begin{array}{l}\text { Interpersonal dynamics where one person exercises personal or positional influence over another person or } \\
\text { group of people }\end{array}$ \\
\hline Development & Interview & $\begin{array}{l}\text { The extent to which personal development occurs through resources found in the work place, informal } \\
\text { learning on-the-job, and formal/informal mentoring }\end{array}$ \\
\hline Inequity & Interview & Perceived differences in how people are treated within the department (e.g., based on gender or status) \\
\hline Research & Interview & The extent to which research is the main priority \\
\hline Department Support & Interview & Tangible task-related assistance and social support received from the department/colleagues \\
\hline Department Values & Interview & $\begin{array}{l}\text { The degree of importance the department places on an action, behavior, or resource (e.g., calculated risks, } \\
\text { money, resourcefulness) }\end{array}$ \\
\hline Common items & Photo & $\begin{array}{l}\text { Standard office supplies and equipment that are used to perform work-related tasks (e.g., printer, stapler, } \\
\text { books, desktop monitor) }\end{array}$ \\
\hline Functionality & Photo & The floor space is designed to maximize utility or encourage user-oriented behavior \\
\hline Resource implications & Photo & $\begin{array}{l}\text { Observable distribution of resources across the department potentially indicating department values and/or } \\
\text { priorities }\end{array}$ \\
\hline
\end{tabular}

exists at different manifested layers of organizational culture. An example of a consistent dimension across both artifacts and interviews was individualism. Individualism refers to the extent to which an individual displayed personally meaningful actions, values, or objects (in the office space) that were not necessarily work related. In some cases, the choice was to not display anything personal, which is another form of individualism (intensity score of 1). While the interview data reflected how people talked about individualized behaviors indicating behavioral norms, the coded office photos validated this dimension through the personalization in the artifacts reflecting individualism. For instance, individualism in the interviews was represented by "faculty are diverse", "people can be themselves", "faculty are very independent", "everyone is doing their own thing", "some people socialize", and "some people don't socialize much." Individualism in the artifacts was represented by family pictures and/or children's artwork, plants, paintings, microwaves, radios, quilts, or coat racks. These types of artifacts appeared in some offices, but not in others, showing the extent to which organizational members complied with this aspect of culture. Both interviews and artifacts that fell within the individualism dimension seemed consistent and conveyed the same message - individualism was okay, if not encouraged, in this culture.

Other examples of shared or overlapping dimensions include collaboration and department politics. Collaboration refers to the degree to which people work with others. Within the interviews, collaboration was represented by "connect with collaborators and mentors", "faculty like to work in groups", and "easy to make connections here." Within the artifacts, collaboration was represented by one or more comfortable guest chairs and at least one extra table (i.e., not an office desk, sometimes a coffee table) visibly not dedicated to continuous office work (e.g., lacked a computer, papers, and phone). The dimension of department politics refers to the display of hierarchy or authority. In the interviews, department politics was represented by statements like "politics are significant in 
the university setting", "there is a noticeable hierarchy", and "there is a distinction between a few powerful faculty and the rest." In the artifacts, department politics was represented by whether office space was shared with another person or not, architectural details of the office, and the degree of newness to the office space. With both collaboration and department politics, although the interviewees' stated they worked with others and that there was a noticeable hierarchy, artifacts confirmed the espoused norm.

The workstyle dimension denotes the way people in the department conduct their work in terms of office use and working norms. For example, in the interview data, workstyle emerged in terms of how frequently respondents use their office space, where people tend to work from (e.g., at the office or at home), and the extent to which people interact in the office. Specifically, respondents reported that "all faculty and staff have offices" and "people mostly work from the office, but also from home." Respondents claimed some people spent more time in the office compared to others, thus, amount of time in the office was dependent on the specific person. However, respondents conveyed a norm that people are "frequently in the office." One respondent noted that it is "easy to get a hold of people and track them down" since offices are typically occupied. The workstyle dimension in the artifact data manifested in terms of the office furniture, office supplies, decorations, and office structure/design. For instance, the dimension was represented by paper or books on desks, organized or unorganized office desks and cabinets, number of filing cabinets or bookcases, number of monitors or computers, size of desks, and configuration of multiple desks (e.g., connected or facing one another). The artifact data seemed to illustrate (literally show) that people work in their offices, validating the interview statements. High intensity scoring (average 4.04) or artifacts for this dimension supported that "people mostly work from the office", indicating high compliance with this espoused norm.

We found similar consistency between artifacts and organizational norms for the remaining overlapping themes, socializing and performance (success). However, evidence from the photo data was less frequent than the dimensions mentioned above. For instance, socializing refers to the ways in which employees talk to one another and interact in non-work related engagements in or outside of work. Artifacts included a bowl of candy on the desk or bookcase. For the interviews, socializing included "a core group goes to happy hours" and "some people eat lunch together". Performance (success) refers to individuals doing their best and demonstrating contributions. Artifacts in this dimension included awards and plaques. In the interview data, comments included "being the best is most important" and "working hard gets rewarded".

There were also several unique artifact dimensions not reflected in the interview data. We turn to those next.

\section{Unique Artifact Dimensions}

Some identified artifacts were thematically separate from interview dimensions. For instance, functionality, which refers to the setting arranged for maximum utility, was a dimension for artifacts but not for interviews. Functionality was displayed by an office without extra cabinets or chairs, furniture against the walls that maximized open floor space, or floor space that was fully used with furniture, but arranged in a way that allowed access (as opposed to so cluttered you cannot get into the room). Across the 31 office spaces, 28 had some indication of arrangement for functional use as noted by the average intensity score of 2.93 . In the interviews, respondents did not refer to arranging their work environment or interactions to maximize utility or performance.

Another dimension unique to artifacts was resource implications. This dimension referred to what appeared to be uneven distribution of resources (e.g., money). For example, some offices had new(er) carpeting and ergonomic furniture as compared to others. Lastly, common items was a dimension developed for the artifact data to reflect the common items found in the photos. These items include desks, chairs, computers, books, doors, and phones. Common items appear to provide an indication of what kind of work is completed (e.g., knowledge-work) and with what type of equipment (e.g., computer, desk, phone).

The occurrence of unique artifact dimensions indicate deep semi-conscious aspects of culture that employees' experience but do not think about when answering questions about culture; they simply take these symbols of culture for granted. Thus, photo coding of artifacts can provide insight into "taken for granted" aspects of culture that might not be easily extracted using other forms of culture assessment, such as interviews or questionnaires.

\section{Unique Interview Dimensions}

Dimensions derived from interviews that were unobserved in the artifacts included development, informal and formal mentoring or learning-on-the-job (e.g., "learn on your own", "was mentored"); department support, social and taskrelated support from coworkers (e.g., "anybody is willing to help", "had onboarding guidance"); department values, importance of department-encouraged behaviors such as 
taking calculated risks and being resourceful (e.g., "everyone in the department is a risk taker", "grant money is important"); inequity, perceived differences in treatment based on gender or status (e.g., "misogyny exists in this department", "male professors get addressed by their full name"); job design, clarity about assigned responsibilities and how aspects of the job appears valued (e.g., "service is expected but not rewarded", "faculty are recognized for research and teaching"); power, interpersonal dynamics where one person exercises personal or position influence over another (e.g., "one group is well protected - given better resources", "a few faculty think they can stomp on their students"); and research, which refers to the main focus of work (e.g., "research is still the first priority", "rewards will always be skewed towards research").

\section{Conclusion}

The extraction of unique dimensions observed in the artifacts which were not associated with interview data, and vice-versa, supports Schein's (1990) contention that one cannot fully understand the culture without assessing multiple layers of culture manifestation and without asking organizational members about their values. Organizational culture is a multi-layer construct representing a complex phenomenon, a socially constructed and shared conscious and subconscious that guides employees' behavior and attitudes. To understand fully how culture is deeply manifested and sustained requires assessing all its layers. While the interview dimensions we found provide a level of richness in understanding behavior within the organization and the values/norms that drive the behavior reflected in some of the artifacts, the dimensions extracted from the artifacts provide unique and complementary information that fills out the culture picture while also providing validity to the interview dimensions. Because artifacts are not constrained by researcher or reacted to by the respondent, and they occur in the field setting, they add validity to the overall culture assessment. In qualitative research, "validity refers to whether the account of a phenomenon reflects the participants' lived experience" (Eby et al., 2009, p. 224). We contend coding artifacts substantially adds to an accurate account of employees' work experience. Additionally, because we use photos of the actual field setting, our approach maximizes ecological validity, hence contributing to external validity (Eby et al., 2009).

Although researchers have used photos as visual data in other domains, such as sociology, our method for coding photos for organizational artifacts assessment is novel, especially within the social sciences (Ray \& Smith, 2012). Photos provide an opportunity to capture artifacts in a contextual snapshot. The snapshot presents multiple benefits, including 1) a framework for comparison across multiple raters, 2) a framework for comparison against other artifacts, and 3) a framework for current and future assessment comparisons and augmentation. Photo coding applied to artifacts can enable researchers to explore a large range of potential artifacts within an organization without burdening organizational members beyond already intense culture assessments. Photo coding also provides a means of capturing context at multiple time points, allowing for observation of artifacts related to organizational changes, or based on stages of organizational operating tempo.

Importantly, cultural artifacts express the alignment between what people may say versus what they do. In our example, a university setting, it may be the disparity between artifacts and espoused values is too small to appreciate the true benefit of coding artifacts. A better example might have been to use a setting where values, such as safety, are talked of highly, but the artifacts, in this example personal protection equipment and rules for public health safety, are unkempt, outdated, or noticeably absent. In such cases, the coding of artifacts would reveal the espoused values do not match the enacted values, a discovery not easily found with interviews alone. As Schein (1990) noted, "If one has access to the organization one will note its artifacts readily but not know what they mean. Of most value in this process will be noting anomalies and things that seem different, upsetting, or difficult to understand" (p. 112; italics in the original). Thus, a valuable contribution of assessing and coding artifacts alongside other assessments of culture is in identifying alignment and/or inconsistencies, bolstering the validity of the overall culture assessment.

\section{Future Research Directions}

The use of visual assessment through photographs of office areas provides an opportunity to enhance replicability, increase the diversity of representative spaces in an organization, and allow for potential observation of change over time in the use and function of organizational space (Ray $\&$ Smith, 2012). We recommend the use of photography to capture office settings under multiple operating scenarios, to include: 1) business as usual, 2) off-season or slow periods, 3) busy or abnormally turbulent periods, 4) periods surrounding organizational changes, and 5) periods during major disruptions to normal operations (such as a pandemic). 
Future research should consider collecting longitudinal data to investigate the reliability of this new method, and to investigate changes over time (especially after an organizational change effort such as a merger).

Future research should take into consideration the multiple levels inherent in organizations by conducting multilevel assessments. Multilevel research may provide insight into differences in norms and artifact representation at each level of the organization. For instance, the type of office furniture, office layout, and opportunity to personalize may mean nothing to workers who spend little time in an office. At senior levels of the organization, an office space, its layout, and use may represent multiple political factors with underlying power dynamics rife with meaning and symbolism. Additionally, researchers might explore technological innovations for improving the photo coding method. For example, software exists for stitching together images to create a multidimensional view of the office space and one that allows the coder to explore the space interactively.

An emerging research agenda may be to consider the implications for artifact coding in era of the COVID-19 pandemic, where numerous companies have changed their office environments and encouraged their knowledge-workers to work virtually from home to slow the spread of the virus. Home offices or spaces that were once a spare bedroom or dining room but now serve as home offices are less likely to have company-related artifacts. Likewise, company office spaces modified with Plexiglas barriers and extra space to accommodate social distancing guidelines may no longer have artifacts that convey company culture, but instead convey the realities of public health concerns. Thus, an important question for researchers exploring culture is, given the disruption of the traditional office work environment due to the pandemic, do organizational culture artifacts still exist, and if so, what do they look like? What about in home offices? If artifact assessment within the home office is considered, researchers must also evaluate the ethics behind soliciting and evaluating photographs of home offices. For example, would photos of the home office violate worker privacy? Although employees may use their home offices to conduct paid work for an organization, these offices are still located within employees' private residencies. Though minimal, available research into privacy concerns with video conferencing suggest the ethics of working virtual due to the pandemic are not simple or resolved (e.g., Park, 2020).
Additionally, whether ethics support it or not, people simply may not be comfortable with that level of sharing, giving others a view of their personal life (Chayka, 2020). In addition to privacy, another concern involves expectations for home office settings and the impact on employee trust and subsequent performance. Organizations that hold high expectations for what constitutes a professional setting or professional appearance must now navigate level of desired control over employees' home office settings. This may lead to conflicts over work-life boundaries, and some employees may not agree with management's expectations for their home office settings, exemplifying issues arising from conceptualizing organizational culture across differing boundaries and work environments.

In summary, photo coding gives researchers the opportunity to assess artifacts and understand this layer of culture in its natural setting. Unobtrusive methods, such as photographs of offices, do not involve employees, providing a nonreactive approach that minimizes interruptions and lost productivity while data are collected (Reader et al., 2020). The method does not require numerous hours of respondents' time, is not restricted by surveys subject to common method bias (Podsakoff et al., 2012), and does not force responses into a particular cultural framework (e.g., CVF, OCP). Our novel application of intensity scoring to photo coding provides nuances to otherwise generic artifact themes, allowing for richer data representation highlighting contextual elements of the office environment. Intensity scores of artifacts may allow for comparison across different departments or functional areas of an organization. Just as the importance of norms may fluctuate within an organization, the value and meaning drawn from artifacts can also fluctuate - a difference that may be discernible through intensity scoring.

Limitations of this approach include that the quality of coding depends on the representativeness and quality of photos. For example, a limitation in $\mathrm{n}$ our study is that we did not sample offices across the entire university. Additionally, artifacts alone cannot explain why people behave the way they do in organizations. Pairing artifact photo coding with other forms of organizational culture assessment aimed at norms/values and underlying assumptions can secure a wellrounded and comprehensive understanding of an organization's culture, which is arguably necessary for developing selection methods, onboarding, training, leadership development, and more, and essential if one is considering changing the culture. 


\section{Appendix}

Flow Chart for Steps of Photo Coding Process

\begin{tabular}{|l|}
\hline Take photographs of \\
artifacts and prepare \\
by blurring identifiers
\end{tabular}

Identify artifacts using

form, function, and social

2 agency; conduct content analysis to assign $1^{\text {st }}$ order codes

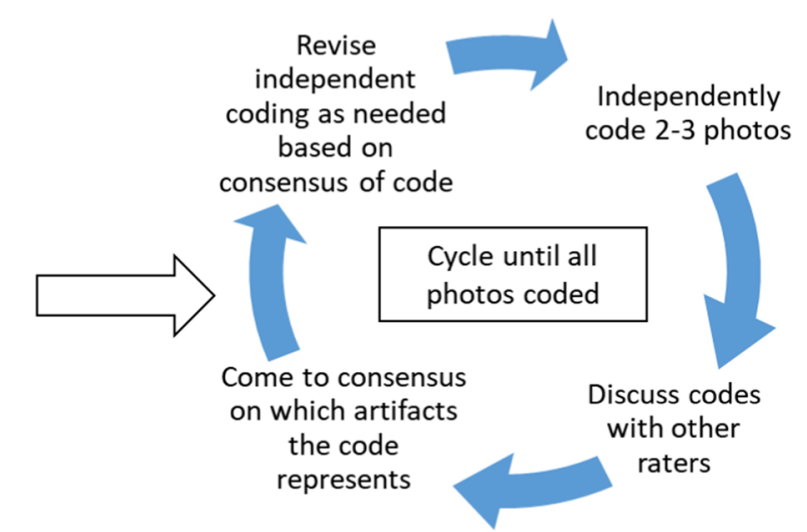

3

\begin{tabular}{c}
\hline Use thematic \\
analyses to develop \\
$2^{\text {nd }}$ order codes \\
\hline
\end{tabular}

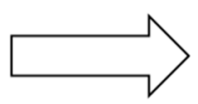

Coders discuss $2^{\text {nd }}$ order codes and come to consensus

Funding This work was supported in part by the National Science Foundation, Engineering Education and Centers, under Grant EEC-1519438.

\section{References}

Akemu, O., \& Abdelnour, S. (2020). Confronting the digital: Doing ethnography in modern organizational settings. Organizational Research Methods, 23(2), 296-321. https://doi.org/10.1177/10944 28118791018

Andrus, J. (2019). Traeger's CEO on cleaning up a toxic culture. Harvard Business Review, 97(2), 33-37.

Bonavia, T. (2006). Preliminary organizational culture scale focused on artifacts. Psychological Reports, 99(3), 671-674. https://doi. org/10.2466/PR0.99.3.671-674

Brewer, J. D. (2004). Using templates in the thematic analysis of text. In C. Cassell \& G. Symon (Eds.), Essential guide to qualitative methods in organizational research (pp. 256-270). Sage.

Campbell, J.-L., \& Göritz, A. (2014). Culture corrupts! A qualitative study of organizational culture in corrupt organizations. Journal of Business Ethics, 120(3), 291-311. https://doi.org/10.1007/ s10551-013-1665-7
Cameron, K. S., Quinn, R. E., DeGraff, J., \& Thakor, A. V. (2006). Competing values leadership: Creating value in organizations. Edward Elgar Publishing. https://doi.org/10.4337/9781847201 560

Charmaz, K. (2006). Constructing grounded theory: A practical guide through qualitative analysis. Sage

Chatman, J. A., \& O'Reilly, C. A. (2016). Paradigm lost: Reinvigorating the study of organizational culture. Research in Organizational Behavior, 36, 199-224. https://doi.org/10.1016/j.riob.2016. 11.004

Chayka, K. (April, 2020). Domestic inferiors: There's no equality in the Zoom home office. Retrieved March 5, 2021 from https://archi ve.curbed.com/2020/4/9/21212323/zoom-backgrounds-coronavirus-culture

Collier, J. (1967). Visual anthropology: Photography as a research method. Holt.

Dacin, M. T., Munir, K., \& Tracey, P. (2010). Formal dining at Cambridge colleges: Linking ritual performance and institutional maintenance. Academy of Management Journal, 53(6), 13931418. https://doi.org/10.5465/AMJ.2010.57318388

Eby, L. T., Hurst, C. S., \& Butts, M. M. (2009). Qualitative research: The redheaded stepchild in organizational and social science research? In C. E. Lance \& R. J. Vandenberg (Eds.), Statistical and methodological myths and urban legends (pp. 219-248). Routledge. 
Fairhurst, G. T., \& Putnam, L. L. (2019). An integrative methodology for organizational oppositions: Aligning grounded theory and discourse analysis. Organizational Research Methods, 22(4), 917-940. https://doi.org/10.1177/1094428118776771

Ghosh, S., \& Srivastava, B. K. (2014). Construction of a reliable and valid scale for measuring organizational culture. Global Business Review, 15(3), 583-596. https://doi.org/10.1177/0972150914 535145

Gioia, D. A., Corley, K. G., \& Hamilton, A. L. (2013). Seeking qualitative rigor in inductive research: Notes on the Gioia methodology. Organizational Research Methods, 16(1), 15-31. https://doi.org/ 10.1177/1094428112452151

Haselhuhn, M. P., Ormiston, M. E., \& Wong, E. M. (2015). Men’s Facial Width-to-Height Ratio Predicts Aggression: A MetaAnalysis. PLoS ONE, 10(4), 1-10. https://doi.org/10.1371/journ al.pone. 0122637

Huhtala, M., Kaptein, M., \& Feldt, T. (2016). How perceived changes in the ethical culture of organizations influence the well-being of managers: A two-year longitudinal study. European Journal of Work and Organizational Psychology, 25(3), 335-352. https:// doi.org/10.1080/1359432X.2015.1068761

Inés Meo, A. (2010). Picturing students' habitus: The advantages and limitations of photo-elicitation interviewing in a qualitative study in the city of Buenos Aires. International Journal of Qualitative Methods, 9(2), 149-171. https://doi.org/10.1177/1609406910 00900203

Jenkins, O. H. (1999). Understanding and measuring tourist destination images. International Journal of Tourism Research, 1(1), 1-15. https://doi.org/10.1002/(SICI)1522-1970(199901/02)1:1\%3c1:: AID-JTR143\%3e3.0.CO;2-L

Jung, T., Scott, T., Davies, H. T. O., Bower, P., Whalley, D., McNally, R., \& Mannion, R. (2009). Instruments for exploring organizational culture: A review of the literature. Public Administration Review, 69(6), 1087-1096. https://doi.org/10.1111/j.1540-6210. 2009.02066.x

Martin, J. (2002). Organizational culture: Mapping the terrain. Sage

Morse, J. M., Barrett, M., Mayan, M., Olson, K., \& Spiers, J. (2002). Verification strategies for establishing reliability and validity in qualitative research. International Journal of Qualitative Methods, 1(2), 13-22. https://doi.org/10.1177/160940690200100202

O'Reilly, C. A., III., Chatman, J., \& Caldwell, D. F. (1991). People and organizational culture: A profile comparison approach to assessing person-organization fit. Academy of Management Journal, 34(3), 487-516.

Ostroff, C., Kinicki, A. J., \& Muhammad, R. S. (2013). Organizational culture and climate. In N. W. Schmitt, S. Highhouse, \& I. B. Weiner (Eds.), Handbook of psychology: Industrial and organizational psychology, Vol. 12, 2nd ed. (pp. 643-676). John Wiley \& Sons, Inc.

Park, Y. J., \& (May, . (2020). A twist of the coronavirus privacy crisis: New lows in privacy. Retrieved March 5, 2021 from https://doi. org/10.2139/ssrn.3601315

Podsakoff, P. M., MacKenzie, S. B., \& Podsakoff, N. P. (2012). Sources of method bias in social science research and recommendations on how to control it. Annual Review of Psychology, 63(1), 539-569. https://doi.org/10.1146/annurev-psych-120710-100452

Potter, W. J., \& Levine-Donnerstein, D. (1999). Rethinking validity and reliability in content analysis. Journal of Applied Communication Research, 27, 258-284. https://doi.org/10.1080/00909 889909365539

Pratt, M. (2009). From the editors. For the lack of a boilerplate: Tips on writing up (and reviewing) qualitative research. Academy of Management Journal, 52(5): 856-862.

Ray, J. L., \& Smith, A. D. (2012). Using photographs to research organizations: Evidence, considerations, and application in a field study.
Organizational Research Methods, 15(2), 288-315. https://doi. org/10.1177/1094428111431110

Reader, T. W., Gillespie, A., Hald, J., \& Patterson, M. (2020). Unobtrusive indicators of culture for organizations: A systematic review. European Journal of Work and Organizational Psychology. https://doi.org/10.1080/1359432X.2020.1764536

Rousseau, D. M. (1990). Assessing organizational culture: The case for multiple methods. In B. Schneider (Ed.), Organizational climate and culture (pp. 153-192). Jossey-Bass.

Saldaña, J. (2009). The coding manual for qualitative researchers. Sage.

Sarrica, M., \& Brondi, S. (2020). Photovoice as a visual-verbal strategy for studying contents and processes of social representations: A participatory project on sustainable energy. Qualitative Research in Psychology, 17(4), 565-586. https://doi.org/10.1080/14780887. 2018.1456587

Saunders, B., Sim, J., Kingstone, T., Baker, S., Waterfield, J., Bartlam, B., Burroughs, H., \& Jinks, C. (2018). Saturation in qualitative research: Exploring its conceptualization and operationalization. Quality \& Quantity, 52(4), 1893-1907. https://doi.org/10.1007/ s11135-017-0574-8

Saunders, J. F., Eaton, A. A., \& Aguilar, S. (2020). From self(ie)objectification to self-empowerment: The meaning of selfies on social media in eating disorder recovery. Computers in Human Behavior. https://doi.org/10.1016/j.chb.2020.106420

Schein, E. H. (1990). Organizational culture. American Psychologist, 45(2), 109-119.

Schein, E. H. (1999). The corporate culture survival guide. San Francisco, CA: Jossey-Bass

Schein, E. H. (2010). Organizational culture and leadership (4th ed.). Jossey-Bass.

Schneider, B., Ehrhart, M. G., \& Macey, W. H. (2013). Organizational climate and culture. Annual Review of Psychology, 64, 361-388. https://doi.org/10.1146/annurev-psych-113011-143809

Shortt, H. L., \& Warren, S. K. (2019). Grounded visual pattern analysis: Photographs in organizational field studies. Organizational Research Methods, 22(2), 539-563

Smollan, R., \& Sayers, J. (2009). Organizational culture, change and emotions: A qualitative study. Journal of Change Management, 9(4), 435-457. https://doi.org/10.1080/14697010903360632

Snyder, E. E., \& Kane, M. J. (1990). Photo elicitation: A methodological technique for studying sport. Journal of Sport Management, 4(1), 21-30. https://doi.org/10.1123/jsm.4.1.21

Trice, H. M., \& Beyer, J. M. (1993). The cultures of work organizations. Prentice-Hall, Inc.

Van Den Berg, P. T., \& Wilderom, C. P. M. (2004). Defining, measuring, and comparing organisational cultures. Applied Psychology: An International Review, 53(4), 570-582. https://doi.org/10. 1111/j.1464-0597.2004.00189.x

Wilhoit Larson, E. (2020). Where is an organization? How workspaces are appropriated to become (partial and temporary) organizational spaces. Management Communication Quarterly, 34(3), 299-327. https://doi.org/10.1177/0893318920933590

Winddance Twine, F. (2006). Visual ethnography and racial theory: Family photographs as archives of interracial intimacies. Ethnic \& Racial Studies, 29(3), 487-511. https://doi.org/10.1080/01419 870600597909

Wong, E. M., Ormiston, M. E., \& Haselhuhn, M. P. (2011). A face only an investor could love: CEOs' facial structure predicts their firms' financial performance. Psychological Science, 22(12), 1478-1483. https://doi.org/10.1177/0956797611418838

Publisher's Note Springer Nature remains neutral with regard to jurisdictional claims in published maps and institutional affiliations. 